Original Article

\title{
OXIDATIVE STRESS-BASED HEPATOTOXICITY OF DULOXETINE IN WISTAR RATS
}

\author{
AKANKSHA MISHRA, AMIT K KESHARI' ${ }^{1}$, ASHOK K SINGH'ㄹ, SIDDHARTHA MAITY², BANKIM NANDY³, \\ SUDIPTA SAHA ${ }^{*}$
}

1Department of Pharmaceutical Sciences, Babasaheb Bhimrao Ambedkar University, Vidya Vihar, Rai Bareli Road, Lucknow 226025, India, ${ }^{2}$ Department of Pharmaceutical Technology, Jadavpur University, Kolkata 700032, India, ${ }^{3}$ Department of Pharmaceutical Sciences, Joyti Vidyapeeth Women's University, Jaipur, Rajasthan

Email: sudiptapharm@gmail.com

Received: 04 Sep 2015 Revised and Accepted: 09 Sep 2016

\begin{abstract}
Objective: Duloxetine, a selective serotonin and noradrenaline reuptake inhibitor used in major depressive disorders, urinary incontinence and diabetic peripheral neuropathic pain. It is reported to be associated with several types of liver injuries, including hepatocellular, cholestatic and mixed hepatocellular-cholestatic patterns. The objective of this study was to assess the effect of duloxetine or its metabolites on oxidative stressinduced liver damages.

Methods: In this study, animals were divided into five groups. In the first group, the only vehicle was given orally for $21 \mathrm{~d}$. The second group has been considered as hepatotoxic control group where Erythromycin was given orally for $14 \mathrm{~d}$ and remaining three groups have been considered as test groups where duloxetine, fluvoxamine and duloxetine along with fluvoxamine were administered orally for $21 \mathrm{~d}$. Liver GSH, oxidised lipid malonaldehyde (MDA), superoxide dismutase (SOD), catalase (CAT), protein carbonyl (PC) and plasma alanine transaminase (ALT), aspartate transaminase (AST) and alkaline phosphatase (ALP) levels were measured to determine the level of hepatotoxicity. Scanning electron microscopy
\end{abstract} (SEM) study of liver tissues was also performed to examine the liver injuries.

Results: GSH and SOD levels were found to be decreased in duloxetine-treated groups with respect to the hepatotoxic control group, whereas increased level of MDA, CAT and PC signify the damages of liver cells. Increased level of plasma ALT, AST and ALP at the same time indicated liver tissue damage. Opposite effects were observed in the case of duloxetine and fluvoxamine-treated groups. SEM of liver tissues revealed that the tissue injury occurred in Duloxetin treated groups, whereas the restoration of normal tissue architecture took place due to the administration of duloxetine and fluvoxamine-treated groups.

Conclusion: Our results collectively indicated that hydroxylated and epoxide metabolites of duloxetine might have hepatotoxic potential due to oxidative stress produced by the release of free radicals or reactive oxygen species.

Keywords: Duloxetine, CYP1A2 enzyme, Hepatotoxicity, Oxidative stress

(C) 2016 The Authors. Published by Innovare Academic Sciences Pvt Ltd. This is an open access article under the CC BY license (http://creativecommons. org/licenses/by/4. 0/) DOI: http://dx.doi.org/10.22159/ijpps.2016v8i11.8857

\section{INTRODUCTION}

Duloxetine (DLX, fig. 1A) [N-methyl- $\gamma$-(1-naphthyloxy)-2-thiophenepropylamine] is a selective serotonin and noradrenaline reuptake inhibitor, approved by the USFDA for the treatment of major depressive disorders. In addition, it is also used in stress-induced urinary incontinence and diabetic peripheral neuropathic pain [1]. DLX is highly bind to plasma proteins ( $>90 \%)$ and mainly metabolised by various cytochrome (CYP) enzymes, such as CYP1A2 and CYP2D6 in humans. Although, the naphthyl ring underwent epoxidation and subsequently formed adduct with glutathione (GSH), but thiophene moiety showed inert after bioactivation [1]. The bioactivation of naphthyl ring mediated through CYP1A2 enzyme corresponds to 4hydroxy DLX, 6-hydroxy-5-methoxy DLX and 4, 6-dihydroxy DLX [4]. Sometimes, naphthyl ring could generate reactive metabolites, i.e. epoxides which may cause hepatotoxicity [2]. The role of the CYP2D6 enzyme during bioactivation of DLX was not prominent in the case of both rats and humans.<smiles>CNCCC(Oc1ccc2ccccc2c1)c1cccs1</smiles>

(A)

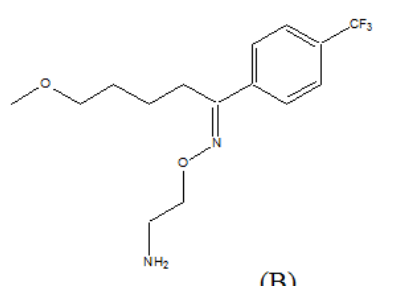

(B)
Fig. 1: Structures of (A) DLX and (B) FLX
Recently, it has been reported that DLX was reported to be associated with several cases of hepatocellular, cholestatic and mixed hepatocellular-cholestatic patterns of liver injuries [3]. Hepatobiliary diseases were estimated to occur in about 8 per 100,000 cases, while elevation of enzyme level increased thrice the value of normal range as observed in 0.9 to $1.7 \%$ of DLX treated subjects $[4,5]$. Idiosyncratic liver damages were estimated to occur about 1-2 per 100,000 cases of exposure in DLX [4]. In a pooled analysis of 17615 subjects, the incidence of serum ALT level was increased three times than normal value [6]. Hanje et al. (2006) reported and explained the cause of fulminant hepatic failure and death during DLX therapy [7]. Taking into all these considerations related to DLX inducing hepatotoxicity, the question arose whether DLX or its metabolites has any role in hepatotoxicity or not? It has been reported that DLX is metabolised by both CYP1A2 and CYP2D6. Therefore, the objective of this study was to evaluate the effect of Duloxetine or its metabolites on oxidative stress-induced hepatotoxicity. In order to further ascertain the oxidative stress-induced hepatotoxicity, docking studies were also performed accordingly.

\section{MATERIALS AND METHODS}

\section{Materials}

Duloxetine (DLX; Batch Number: DL0040713) and Fluvoxamine (FLX; fig. 1B, Batch Number: LT-OFLM/014/12-13) were received from Indian companies namely Hetero Drugs Limited, Hyderabad, and Mehta API Pvt Ltd, Mumbai, respectively. Disodium ethylenediamine tetraacetic acid (EDTA), disodium hydrogen phosphate, potassium dihydrogen phosphate, sodium citrate and 
trichloroacetic acid were purchased from SD Fine Chemicals, Mumbai, India. 5, 5'-dithiotris-2-nitro benzoic acid, tris buffer, sodium carbonate, glacial metaphosphoric acid, sodium potassium tartrate and sodium chloride were purchased from Loba Chemicals, New Delhi, India. Erythromycin stearate (ERY) was obtained from Himedia, Mumbai, India. All the solvents, reagents and chemicals were of analytical grades with $99 \%$ purity and in-house distilled water was used throughout the experiment.

\section{Docking studies}

Docking studies of DLX were performed using Argus lab, Pyrx virtual screening 0.8 and Autodock 4.0 along with Autodock vina. Before the docking study, we identified the active site domain using DogP active site recognize where the ligand has been shown the best configuration. Later, grid box was set according to previously recognised active site amino acid sequence. Finally, their binding affinity $(\mathrm{kcal} / \mathrm{mol})$ and counting of probable hydrogen bonds were evaluated.

\section{Animal grouping and experimental design}

Male Wistar rats (weighing 90-140 g) were purchased from Animal House, CSIR-CDRI, Lucknow, India (Approval No. UIP/IAEC/ 2014/FEB./07) and were kept in polypropylene cages under standard conditions of temperature $\left(25 \pm 1^{\circ} \mathrm{C}\right)$ with $12 \mathrm{~h}$ light and dark conditions, diet and water ad libitum for $7 \mathrm{~d}$. Animals were randomised and divided into following 5 groups having 6 animals in each group $(n=6)$. Rats were kept fasted overnight before starting the experiment with free excess to water. Drugs were dissolved separately in distilled water as per the following treatment schedule. The first group served as normal control where animals were given only vehicle orally ( $1 \mathrm{ml} / \mathrm{kg} \mathrm{BW})$ for $21 \mathrm{~d}$.

The second group has been considered as hepatotoxic control, where ERY was given orally $(100 \mathrm{mg} / \mathrm{kg}$ BW, served as hepatotoxicity control) for $14 \mathrm{~d}$ [8]. The remaining three groups have been considered as test groups where DLX, FLX and DLX+FLX were administered orally in doses of 10,30 and $10+30 \mathrm{mg} / \mathrm{kg}$ body weight, respectively for $21 \mathrm{~d}[9,10]$. On $14^{\text {th }}$ (for the hepatotoxic control group) and $21^{\text {st }}$ days, blood samples were collected from retro-orbital plexus and centrifuged to separate plasma and kept at $-20{ }^{\circ} \mathrm{C}$ for further biochemical estimations. Rats from each group were sacrificed by cervical dislocation; livers were removed and kept in $-20^{\circ} \mathrm{C}$ for further biochemical estimation.

\section{Estimation of plasma ALT, AST and ALP}

Plasma ALT, AST [11] and ALP [12] were estimated according to the method as described earlier with slight modifications using specific assay kits obtained from Excel Diagnostics Pvt. Ltd., Hyderabad, India.

\section{Estimation of Tissue GSH, CAT, MDA, SOD, and PC}

Tissue GSH [13], CAT [14], MDA and SOD [15], and PC [16] levels were estimated as per the method reported earlier with or without slight modifications.

\section{Scanning electron microscopic (SEM) study of liver tissue}

Rat liver samples were mixed with $2.5 \%(\mathrm{v} / \mathrm{v})$ of glutaraldehyde and were kept at $4{ }^{\circ} \mathrm{C}$ for $2-6 \mathrm{~h}$. Then, the samples were washed with 0.1 (M) phosphate buffer 3 times for 15 min interval. After that, 1\% $(\mathrm{w} / \mathrm{v})$ osmium tetroxide was added to it and kept for $2 \mathrm{~h}$ at $4{ }^{\circ} \mathrm{C}$ and the samples were washed with $0.1(\mathrm{M})$ phosphate buffer 3 times for 15 min interval. Later, the specimens were dehydrated by using an increase in the percentage of drying $(30 \%, 50 \%, 70 \%, 90 \%, 95 \%$, and $100 \% \mathrm{v} / \mathrm{v}$ ) to remove excess water from the samples at $4{ }^{\circ} \mathrm{C}$ for about 30 min period. After that, all specimens were dried in air and the critical point of drying was maintained at $31.5^{\circ} \mathrm{C}$ and pressure at 1100 psi. Finally, the samples were mounted onto the aluminium stubs with adhesive tape and observed the images using scanning electron microscope (JSM-6490LV. Jeol, Japan).

\section{Statistical analysis}

Statistical analysis was carried out using GraphPad Prism 5.0 (Graph Pad Software, San Diago, CA). All results were expressed as mean \pm Standard deviation (SD). The data were analysed by one-way ANOVA (analysis of variances) followed by Bonferroni multiple comparison tests. For biochemical estimations, statistical significance differences were considered with respect to control group $(\mathrm{aP}<0.05, \mathrm{bP}<0.01, \mathrm{cP}<0.001)$.

\section{RESULTS}

\section{Docking studies}

Docking images of DLX along with two target enzymes has been shown in fig. 2. DLX exhibited good binding affinity with CYP1A2 enzyme (value-10.2 kcal/mol and one H-bond) whereas lower binding affinity was observed in the case of CYP2D6 (value-7.5 $\mathrm{kcal} / \mathrm{mol}$ and no H-bond) (table 1).

Table 1: Binding affinities of DLX with human CYP1A2 AND CYP2D6. Comparatively, studies were performed by using various commercially available virtual Dockers

\begin{tabular}{lllll}
\hline Receptor & $\begin{array}{l}\text { Affinity } \\
\text { (kcal/mol) } \\
\text { Auto dock }\end{array}$ & $\begin{array}{l}\text { Affinity } \\
\text { (kcal/mol) } \\
\text { Argus lab }\end{array}$ & $\begin{array}{l}\text { Affinity } \\
\text { (kcal/mol) } \\
\text { Pyrx 8.0 }\end{array}$ & $\begin{array}{l}\text { Amino acids involved } \\
\text { in interactions }\end{array}$ \\
\hline Cytochrome 450 1A2 & -10.2 & -14.97 & -9.7 & $\begin{array}{l}\text { H- } \\
\text { bonds }\end{array}$ \\
Cytochrome 450 2D6 & -7.5 & -11.80 & -8.1 & $\begin{array}{l}\text { ASP313, LEU144 } \\
\text { THR349, LYS345, GLU348, THR367, PR0366, THR438, }\end{array}$ \\
\hline
\end{tabular}
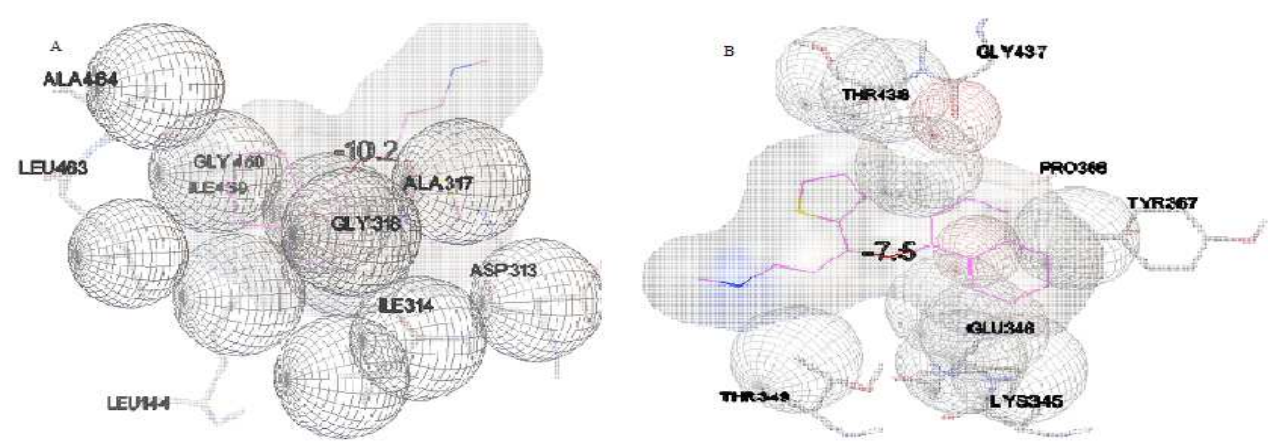

Fig. 2: Docking images of (A) DLX with human CYP1A2 (2HI4) and (B) DLX with human CYP2D6 (2F9Q). The round mesh circular showed the binding affinity of ligand with amino acids involved in binding poses 


\section{Plasma ALT, AST and ALP}

ALT level was slightly higher in DLX $(\sim 57 \mathrm{U} / \mathrm{ml})$ treated group than normal control group $(\sim 40 \mathrm{U} / \mathrm{ml})$ as shown in table 2 . ALT $(\sim 37$ and $32 \mathrm{U} / \mathrm{ml}$ ) level in plasma was found to be decreased in both FLX and DLX+FLX treated groups. ERY acted as a hepatotoxic control, which demonstrated the higher concentration of ALT in plasma.
There was a significant increase in plasma AST level in both ERY $(\sim 182 \mathrm{U} / \mathrm{ml})$ and DLX treated groups $(\sim 174 \mathrm{U} / \mathrm{ml})$. AST level $(\sim 150$ $\mathrm{U} / \mathrm{ml}$ ) was closer to normal control after FLX and DLX+FLX treated groups. A similar result of plasma concentration of ALP was higher in both ERY and DLX treated groups. FLX and DLX+FLX treated groups also showed the similar higher concentration of plasma ALP in compared to normal control (table 2).

Table 2: Various enzyme concentrations in plasma

\begin{tabular}{llll}
\hline Groups & ALT (U/ml) & AST (U/ml) & ALP (U/ml) \\
\hline Control & $40.10 \pm 2.71$ & $150.00 \pm 7.62$ & $830.53 \pm 8.98$ \\
ERY & $56.37 \pm 1.42$ & $182.37 \pm 8.01$ & $956.93 \pm 4.55$ \\
DLX & $57.23 \pm 2.39^{\mathrm{a}}$ & $174.2 \pm 7.82^{\mathrm{a}}$ & $914.67 \pm 6.88^{\mathrm{b}}$ \\
FLX & $37.5 \pm 1.98$ & $143.5 \pm 7.95$ & $820.33 \pm 9.53$ \\
DLX+FLX & $32.6 \pm 2.82^{\mathrm{a}}$ & $147.83 \pm 8.06$ & $780.95 \pm 1.18$ \\
\hline
\end{tabular}

Data were presented as mean $\pm \mathrm{SD}(\mathrm{n}=6)$. Statistically, significant differences were observed between control and test groups [one way-ANOVA followed by Bonferroni multiple comparison test; $\left.\left(\mathrm{a} P<0.001,{ }^{\mathrm{b}} P<0.01\right)\right]$

\section{Biochemical estimations in liver tissues}

In order to understand the mechanism of hepatotoxicity of DLX in Wistar rats, various oxidative stress-related parameters like GSH, MDA, SOD, CAT and PC in liver tissues were measured. As depicted in table 3 , it was observed that GSH level was found to be decreased in DLX treated group. DLX and DLX+FLX treated groups also showed no toxic effect because of similar concentrations of biochemical parameters as in normal control. The level of MDA was higher in both ERY and DLX treated groups ( $\sim 2.0 \mathrm{nM} / \mathrm{mg}$ of protein $)$ as shown in table 3. This concentration again normalised for FLX and
DLX+FLX treated groups. Similar trends were also observed for PC assay where the formation of PC was higher in ERY and DLX treated groups (table 3). In order to determine the oxidative stress-based hepatotoxicity, CAT and SOD enzyme level was measured separately. CAT is most abundant in the liver, which is mainly responsible for the catalytic decomposition of $\mathrm{H}_{2} \mathrm{O}_{2}$. Increase in concentration of $\mathrm{H}_{2} \mathrm{O}_{2}$ in DLX treated group depicted that there was less amount of CAT enzyme available in the tissues to decompose $\mathrm{H}_{2} \mathrm{O}_{2}$ (table 3). It was observed that SOD enzyme level was also decreased in DLX treated group in compared to normal control, FLX and DLX+FLX treated groups.

Table 3: Various oxidative stress parameters in liver

\begin{tabular}{|c|c|c|c|c|c|}
\hline Groups & $\begin{array}{l}\text { SOD }(U / \mathrm{mg} \text { of } \\
\text { Protein) }\end{array}$ & $\begin{array}{l}\mathrm{CAT}\left(\mathrm{nM} \mathrm{H}_{2} \mathrm{O}_{2} \text { decomposed } / \mathrm{min} / \mathrm{mg}\right. \\
\text { of protein ) }\end{array}$ & $\begin{array}{l}\text { GSH }(\mu \mathrm{M} / \mathrm{mg} \text { of } \\
\text { Protein) }\end{array}$ & $\begin{array}{l}\text { TBARS } \\
\text { (nM of MDA/mg of protein) }\end{array}$ & $\begin{array}{l}\mathrm{PC}(\mu \mathrm{g} / \mathrm{mg} \text { of } \\
\text { protein })\end{array}$ \\
\hline Control & $2.23 \pm 0.13$ & $75.20 \pm 4.51$ & $60.67 \pm 3.64$ & $1.79 \pm 0.29$ & $0.41 \pm 0.03$ \\
\hline ERY & $1.11 \pm 0.06$ & $58.33 \pm 5.50$ & $42.15 \pm 2.52$ & $5.36 \pm 0.22$ & $0.69 \pm 0.04$ \\
\hline DLX & $1.17 \pm 0.07 \mathrm{a}$ & $97.88 \pm 5.87^{\mathrm{a}}$ & $37.80 \pm 2.96^{\mathrm{a}}$ & $5.12 \pm 0.20^{\mathrm{a}}$ & $0.65 \pm 0.05^{a}$ \\
\hline FLX & $2.17 \pm 0.18$ & $70.87 \pm 5.39$ & $63.01 \pm 2.68$ & $1.41 \pm 0.20$ & $0.41 \pm 0.03$ \\
\hline DLX+FLX & $1.80 \pm 0.10^{\mathrm{a}}$ & $34.24 \pm 4.05^{\mathrm{a}}$ & $60.46 \pm 4.82$ & $2.43 \pm 0.14^{\mathrm{a}}$ & $0.42 \pm 0.02$ \\
\hline
\end{tabular}

Data represented as mean \pm SD $(n=6)$. Statistically, significant differences were observed between control and test groups [one way-ANOVA followed by Bonferroni multiple comparison test; $\left.{ }^{\mathrm{p}} \mathrm{p}<0.001\right]$

\section{SEM analysis of liver}

SEM analysis showed the presence of lesions in DLX treated group, whereas, it was absent in both FLX and DLX+FLX treated groups (fig. 3).

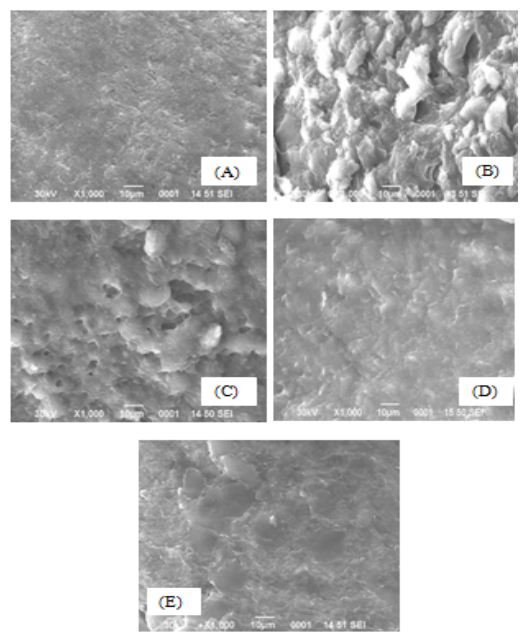

Fig. 3: SWM photomicrographs of the liver tissues (A) Control,

(B) ERY, (C) DLX, (D) FLX and (E) DLX+FLX. Tissue necrosis was observed in ERY and DLX treated rats which were less prominent in both FLX and DLX+FLX treated rats

\section{DISCUSSION}

Most of the hepatotoxic drugs are generally involved in increasing levels of liver enzymes and GSH level due to oxidative stress induced by some specific drugs, whereas some other drugs may take part in the alteration of liver mitochondrial functions and expression of liver genes [17-19]. Mechanism of oxidative stress also plays an important role in causing hepatotoxicity produced by some drugs like acetaminophen [20]. It is assumed that some orally administered drugs are involved in the generation of free radicals which may further elevate the tissue TBARS, PC and may reduce the CAT, GSH and SOD levels in liver, and increased level of plasma ALT, AST and ALP were collectively responsible for liver damages.

Orally active DLX was metabolised by CYP1A2 to corresponding hydroxylated and epoxide metabolites which had a tendency to bind with GSH $[1,2]$. This practical data was also confirmed by docking studies where we found that CYP1A2 was the major enzyme for DLX metabolism (fig. 2 and table 1). Taking into consideration of above observations, it was questionable whether parent DLX is hepatotoxic or its metabolites. To get the actual answer, metabolism of DLX using FLX (CYP1A2 inhibitor) was conducted, and various biochemical parameters were evaluated.

Our results collectively suggested that all the enzyme levels were higher for DLX treated groups than control group whereas this level is slightly lower for both FLX and DLX+FLX treated groups as shown in table 2. Both AST and ALT are the liver enzymes which is responsible for transamination of amino acids, whereas ALP is responsible for catalysis of organic phosphate esters. These are the key enzymes of 
liver, which are extracted out during liver damages [16, 21]. The increase of these enzymes in plasma during DLX treatment indicated the hepatic damage, which was further improved by FLX treatment. This was an indirect indication of liver damage, but it could not be explained how DLX produced toxicity in the liver after oral administration

The DLX treated rats depleted more reduced glutathione (GSH) than FLX and DLX+FLX treated groups (table 3). GSH is a tripeptide, which is most abundant in all tissues including liver. GSH has a major role in oxidation-reduction process, resulting in the formation of disulfide glutathione (GSSG) [22] during oxidative damage. Reduction of GSH level by DLX is an indication of oxidative stress-induced liver damage, which was improved during FLX treatment. The decrease in the levels of GSH in DLX treated rats represented the higher utilisation of GSH during oxidative damage which was completely restored during a single dose of FLX and combined dose of FLX with DLX.

To prove the oxidative stress induced hepatotoxicity, the tissue MDA levels were also performed. Oxidation of lipids is another important parameter to measure the oxidative stress in living body [17]. From the result; it was observed that tissue MDA level was higher for DLX treated group, which was again restored to a normal level during FLX, and DLX+FLX treated rats (table 3). The Higher amount of MDA formation during DLX treatment was directly represented the oxidative damage of liver cells. Thus, the results indicated that DLX might be responsible for hepatotoxicity due to oxidative damages.

In order to understand the relationship between oxidative stress and hepatotoxicity, PC assay was performed where a higher amount of PC was formed than DLX treated groups (table 3). The carboxyl group of protein become oxidised due to the formation of reactive oxygen species [23] and converted to PC, which is an important marker for oxidative stress. As depicted in table 3, DLX treated groups formed more PC than FLX and DLX+FLX treated groups which were an important indication of oxidative stress-induced liver damages.

In order to further understand the mechanism of oxidative stress, both CAT and SOD enzyme levels in liver were measured. The enzyme CAT is also most abundant in the liver which catalyses the conversion of $\mathrm{H}_{2} \mathrm{O}_{2}$ to corresponding oxygen and water. The action of this enzyme is reduced due to the presence of peroxides and reactive oxygen species [24, 25]. $\mathrm{H}_{2} \mathrm{O}_{2}$ levels were measured, and values were compared between various treated groups. Increase in concentration of $\mathrm{H}_{2} \mathrm{O}_{2}$ in DLX treated sample depicted that there were less amount of CAT enzyme available in the tissue to decompose the $\mathrm{H}_{2} \mathrm{O}_{2}$ with respect to control and other treated groups (table 3). This assay indirectly indicated that oral administration of DLX reduced the level of CAT enzyme in the liver. Separately, the estimation of SOD levels in liver was performed. The SOD levels were also decreased in DLX treated groups, but the level of this enzyme became normal in FLX and DLX+FLX treated rats (table 3).

For direct evidence of liver damages, SEM analyses of liver tissues were performed (fig. 3) and damages of liver tissues were observed in DLX treated rats which were absent in FLX, and DLX+FLX treated groups.

\section{CONCLUSION}

The hepatotoxicity of DLX might be due to oxidative stress produced by hydroxylated and epoxide metabolites, which may release free radicals or reactive oxygen species. Further studies in this context, such as preparation of hydroxylated and epoxide metabolites and measurement of their hepatotoxic potential are beyond the scope of this study.

\section{ACKNOWLEDGEMENT}

Dr. Sudipta Saha (Corresponding Author) would like to thank the University Grants Commission (UGC), New Delhi, India, for providing UGC Start-Up-Grant [Grant No. F. 20-1/2012 (BSR)/20-7 (15)/2012 (BSR)].

\section{CONFLICT OF INTERESTS}

Authors declare that they have no conflict of interest.

\section{REFERENCES}

1. Patel DS, Deshpande SS, Patel CG, Singh S. Duloxetine: a dualaction antidepressant. Indo Global J Pharm Sci 2011;1:63-76.
2. Chan CY, New LS, Ho HK, Chan ECY. Reversible time-dependent inhibition of cytochrome P450 enzymes by duloxetine and inertness of its thiophene ring towards bioactivation. Toxicol Lett 2011;206:314-24.

3. Wernicke J, Pangallo B, Wang F. Hepatic effects of duloxetineI: non-clinical and clinical trial data. Curr Drug Saf 2008;3:132-42.

4. Wernicke J, Acharya N, Strombom I. Hepatic effects of duloxetine-II: spontaneous reports and epidemiology of hepatic events. Curr Drug Saf 2008;3:143-53.

5. McIntyre RS, Panjwani ZD, Nguyen HT, Woldeyohannes HO, Alsuwaidan M, Soczynska JK. The hepatic safety profile of duloxetine: a review. Expert Opin Drug Metab Toxicol 2008;4:281-5.

6. Vuppalanchi R, Hayashi PH, Chalasani N, Fontana RJ, Bonkovsky H, Saxena R, et al. Duloxetine hepatotoxicity: a caseseries from the drug-induced liver injury network. Aliment Pharmacol Ther 2010;32:1174-83.

7. Hanje AJ, Pell LJ, Votolato NA, Frankel WL, Kirkpatrick RB. Case report: fulminant hepatic failure involving duloxetine hydrochloride. Clin Gastroenterol Hepatol 2006:4;912-7.

8. Nassr AH, Hameid A. Protective role of dimethyl diphenyl bicarboxylate (DDB) against erythromycin-induced hepatotoxicity in male rats. Toxicol In Vitro 2007;21:618-25.

9. Yamauchi M, Tatebayashi T, Nagase K, Kojima M, Imanishi T. Chronic treatment with Fluvoxamine desensitizes $5-\mathrm{HT}_{2} \mathrm{C}$ receptor-mediated hypolocomotion in rats. Pharmacol Biochem Behav 2004:78;683-9.

10. Calabrese F, Molteni R, Cattaneo A, Macchi F, Racagni G, Gennarelli $\mathrm{M}$, et al. Long-term duloxetine treatment normalises altered brain-derived neurotrophic factor expression in serotonin transporter knockout rats through the modulation of specific neurotrophin isoforms. Mole Pharmacol 2010;77;846-53.

11. Reitman S, Frankel S. A colorimetric method for the determination of SGOT and SGPT. Am J Clin Pathol 1957:28;53-6.

12. Tietz NW. Fundamentals of clinical chemistry. $2^{\text {nd }}$ Ed. WB Saunders Company: Philadelphia; 1976. p. 602-4.

13. Rehman I, Kode A, Biswas SK. Assay for quantitative determination of glutathione and glutathione disulphide levels using enzymatic recycling methods. Nat Protoc 2007:1;3159-65.

14. Claiborne A. Catalase activity. CRS Hand Book of Methods for Oxygen Radical Research. Greenwald RA. CRC Press: Boca Raton, USA; 1985. p. 283-4.

15. Lodhi RL, Maity S, Kumar P, Saraf SA, Keith was G, Saha S. Evaluation of the mechanism of hepatotoxicity of leflunomide using albino Wistar rats. Afr J Pharm Pharmacol 2013;7:1625-31.

16. Reznick AZ, Packer L. Oxidative damage to proteins: spectrophotometric method for carbonyl assay. Method Enzymol 1994;233:357-63.

17. Russmann S, Kullak-Ublick GA, Grattagliano I. Current concepts of mechanisms in drug-induced hepatotoxicity. Curr Med Chem 2009;16:3041-53.

18. Boverhof DR, Burgoon LD, Tashiro C, Chittim B, Harkema JR, Jump DB, et al. Temporal and dose-dependent hepatic gene expression patterns in mice provide new insights into TCDDmediated hepatotoxicity. Toxicol Sci 2005;85:1048-63.

19. Troudi A, Samet AM, Zeghal N. Hepatotoxicity induced by gibberellic acid in adult rats and their progeny. Exp Toxicol Pathol 2010;62:637-42.

20. Reid AB, Kurten RC, McCullough SS, Brock RW, Hinson JA. Mechanisms of acetaminophen-induced hepatotoxicity: role of oxidative stress and mitochondrial permeability transition in freshly isolated mouse hepatocytes. J Pharmacol Exp Ther 2005;312:509-16.

21. Vetriselvan S, Victor R, Muthappan M, Gnanasekaran D, Chellappann DS. Hepatoprotective effects of aqueous extract of Andrographis paniculata against $\mathrm{ccl}_{4}$ induced hepatotoxicity in albino Wistar rats. Asian J Pharm Clin Res 2011;4:93-4. 
22. Saha S. Hepatotoxicity of thiazolidinedione antidiabetic drugs: a structural toxicity relationship studies. National University of Singapore, Ph. D. thesis; 2010. p. 1-137.

23. Suzuki YJ, Carini M, Butterfield DA. Protein carbonylation. Antioxid Redox Signal 2010:12;325-7.

24. Baudrimont I, Ahouandjivo R, Creppy EE. Prevention of lipid peroxidation induced by ochratoxin an in vero cells in culture by several agents. Chem Biol Interact 1997:104;29-40.
25. Reiter RJ, Tan D, Osuna C, Gitto E. Actions of melatonin in the reduction of oxidative stress. J Biomed Sci 2000:7;444-58.

\section{How to cite this article}

- $\quad$ Akhansha Mishra, Amit K Keshari, Ashok K Singh, Siddhartha Maity, Bankim Nandy, Sudipta Saha. Oxidative stress-based hepatotoxicity of duloxetine in wistar rats. Int J Pharm Pharm Sci 2016;8(11):28-32. 